\title{
Household-level food and nutrition insecurity and its determinants in eastern India
}

\author{
Shinoj Parappurathu ${ }^{1, *}$, Anjani Kumar ${ }^{2}$, Cynthia Bantilan $^{3}$ and \\ Pramod Kumar Joshi ${ }^{2}$ \\ ${ }^{1}$ ICAR-Central Marine Fisheries Research Institute, Kochi 682 018, India \\ ${ }^{2}$ International Food Policy Research Institute, South Asia Office, New Delhi 110 012, India \\ ${ }^{3}$ International Crops Research Institute for the Semi-Arid Tropics, Patancheru 502 324, India
}

\begin{abstract}
Past studies have reported serious levels of food insecurity and under-nutrition existing in the eastern belt of India. This study specifically examined the food consumption pattern, levels of nutrition intake and nutrient intake gap of sample households in 12 villages of Eastern India based on data collected during the agricultural year 2011-12. The results point to serious levels of nutrient intake deficit in the sample villages, though with notable disparities in its level of incidence. Major socio-economic and demographic variables that determine the calorie deficit status of the households were identified, the knowledge of which is important while planning interventions.
\end{abstract}

Keywords: Household food security, food policy, calorie intake, under-nutrition.

TwO integral objectives of India's agricultural policy after the inception of planned development (from 1950) have been to raise food production to sustainable levels and to improve food availability to the masses. The green revolution technologies have succeeded in raising food production within a short span of two decades to appreciable levels and the subsequent initiatives have ensured a steady growth in food production matching with the increase in population. Demonstrably, the total food grain production in the country increased nearly five times to reach 252.7 million tonnes, in 2014-15, from a level of 50.8 million tonnes in 1950 (ref. 1). Consistent with the larger goal of ensuring food security at micro level, the government intervention in food grain marketing was initiated in the mid-sixties. However, in spite of administering a number of measures such as subsidized distribution of food grains, open market operations, mid-day meal scheme, food for work programme, etc. over the past six decades, the goal of ensuring food availability to millions of poor people across the country at affordable prices has remained more or less elusive. The limited access of affordable food for a large majority of people has put India in the league of countries with the worst levels of food insecurity in the world. Evidently, India ranks 97

*For correspondence. (e-mail: pshinoj@gmail.com) among 118 countries covered in the Global Hunger Index 2016, with the food security status designated as 'serious'2. The Rapid Survey on Children (RSoC), 201314 (ref. 3) estimated that nearly $38.7 \%$ of children under five in India are stunted, $15.1 \%$ are wasted and $29.4 \%$ underweight. Similarly, $44.7 \%$ of adolescent girls (15-18 years) in the country are found to be 'thin' (with body mass index less than $\left.18.5 \mathrm{~kg} / \mathrm{m}^{2}\right)^{3}$.

The situation is more alarming in many under developed states of India, particularly concentrated in the eastern region like Bihar, Odisha, Jharkhand and Chhattisgarh. The RSoC data reveals that nearly $40-50 \%$ of children under 5 years of age in the above states are stunted and 15-18\% wasted. Adolescent girls who are found to be 'thin' in these states ranged between $40 \%$ and $50 \%$. Gulati et al. ${ }^{4}$ classified the various Indian states based on two indices of malnutrition namely, Normalized Adult Malnutrition Index (NAMI) and Normalized Child Malnutrition Index (NCMI) and found that all the eastern states fell in the top two categories of malnutrition, with Bihar faring the worst among them. A similar study conducted by M. S. Swaminathan Research Foundation ${ }^{5}$ that classified various Indian states based on a composite index of food insecurity also came out with comparable findings. Such prevalence of food insecurity and malnutrition in eastern India is a stark reminder that various government sponsored measures to alleviate food shortage in the poverty ridden pockets have actually not reached the targeted population. Till recently, the Public Distribution System (PDS) has been faring the worst in Bihar, Odisha and Jharkhand with reportedly high prevalence of targeting errors and unauthorized diversion of PDS food grains, though the initiatives after 2010 have raised hope in reviving them ${ }^{6-8}$. Given the above scenario, this study attempts to comprehensively assess the level of food and nutrition insecurity existing in three eastern states of India namely, Bihar, Jharkhand and Odisha with the help of household-level primary surveys conducted in select villages. The paper is organized in four sections. The section after introduction deals with data and methodology used for the study. The main findings and corresponding discussion are presented next, followed by conclusions and policy implications. 


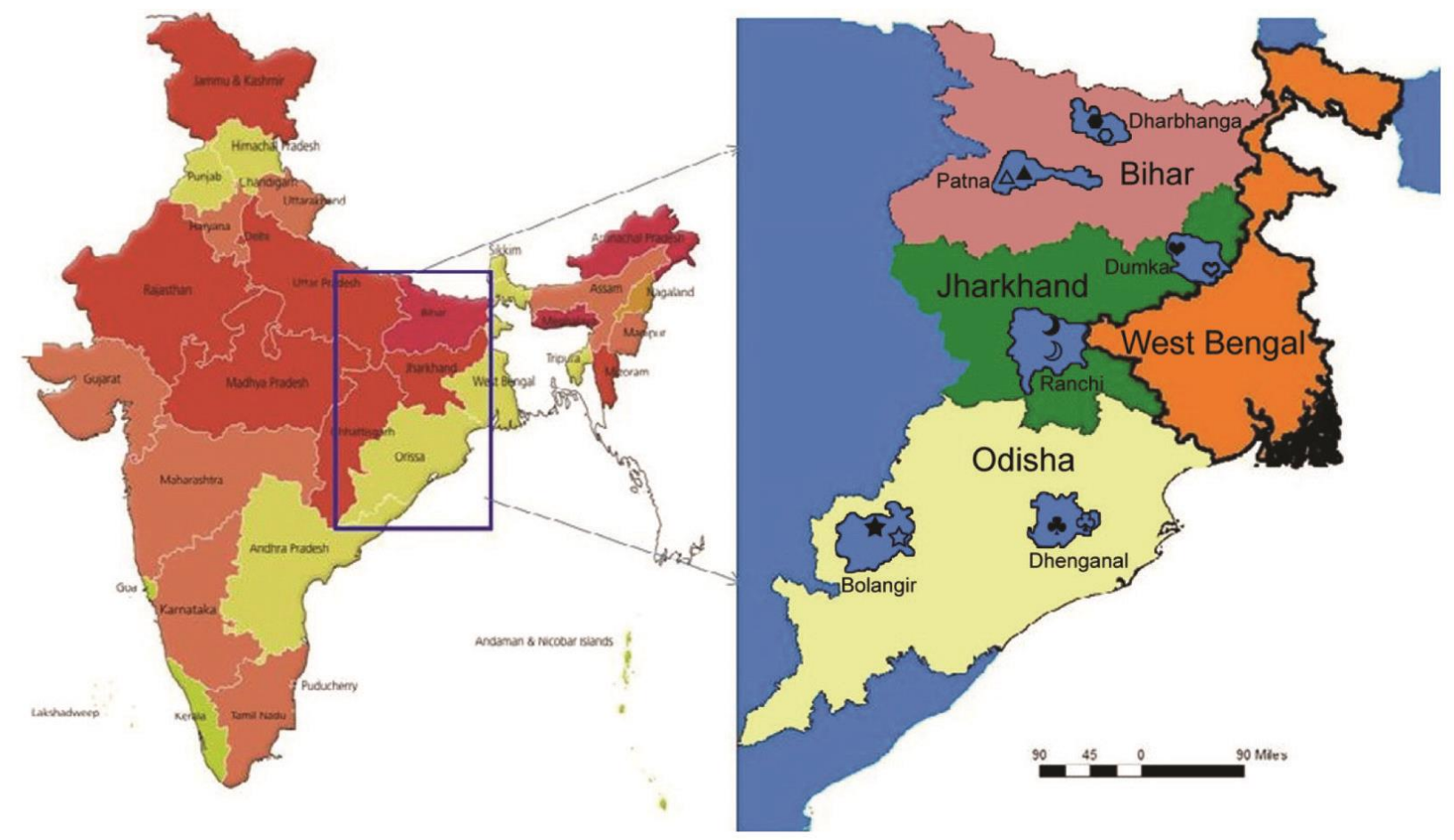

Figure 1. Map showing geographic locations of selected villages in Bihar, Jharkhand and Odisha states of India. $\Delta$, Arap; $\boldsymbol{\Delta}$, Bagha-

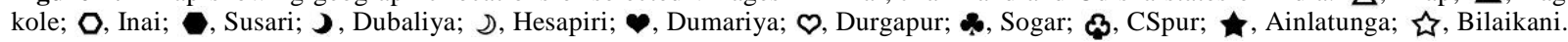

\section{Materials and methods}

\section{Study area and sampling framework}

The study was carried out in 12 villages spread across three states in eastern India (Arap and Bhagakole villages of Patna district and Susari and Inai villages of Darbhanga district of Bihar state; Dubaliya and Hesapiri villages of Ranchi district and Dumariya and Durgapur villages of Dumka district of Jharkhand state; and Sogar and Chandrasekhapur (CSpur) villages of Dhenkanal district and Ainlatunga and Bilaikani villages of Bolangir district of Odisha state). The geographical locations of the selected villages are illustrated in Figure 1 and their socioeconomic and demographic characteristics are abstracted in Appendix 1 (online). Data used was collected through primary surveys conducted under the Village Level Studies (VLS) (The VLS are longitudinal surveys initiated by the ICRISAT in 1975 in 10 Indian villages which continued till 1985. The surveys were re-opened in 2002 in the initial six villages, and later widened to 12 villages in the eastern India with funding from Bill and Melinda Gates Foundation. The VLS data however cannot be treated as representative due to the relatively small sampling coverage.). From each village, 40 households were selected (480 households from 12 villages) and monitored on a sustained basis. The selected households were categorized into various farm-size classes based on the size of land they possessed. First, all selected households within a village, possessing land area less than or equal to 0.5 acres were classified as 'marginal' households. The remaining households were categorized into tertile groups, each containing a third of the sample. The bottom, middle and top tertile groups were referred to respectively as 'small', 'medium' and 'large' households.

The study specifically examines the food consumption pattern, levels of nutrient intake and nutrition gaps of households in the selected villages pertaining to the agricultural year 2011-12 (July 2011 to June 2012). The consumption data in terms of quantity of food items consumed by respondent households was recorded based on 30-day recall period. The recall was administered at monthly intervals to the heads of the households, who responded to the questions in consultation with female members of the family, as long as they resided in the village. The investigators resided in the villages during data collection and sensitized the respondents to keep a regular record of their day-to-day consumption, thereby minimizing possible sampling bias. See Appendix 2 (online) for the detailed questionnaire used for data collection.

\section{Analytical framework}

The food consumption data mentioned above was used to estimate the calorie and nutrient intake at household level. The nutrient chart provided by the National Sample 
Survey Organization, Government of India ${ }^{9}$ as well as the detailed chart on nutritive value of Indian foods available in ref. 10 were used for converting the quantity consumption of each food item to its equivalent calorie and other nutrients (protein, fat, iron, zinc, $\beta$-carotene, thiamine, riboflavin, niacin, folic acid and vitamin C). Each household was subsequently assessed for its 'nutrient gap' status which can be defined as the degree to which the average nutrient consumption of the household negatively deviates from the dietary intake norm computed based on Recommended Dietary Allowances (RDA). This was done by comparing the household average of the actual nutrition intake of its members with respect to the RDA for individuals belonging to different age group, sex and activity levels ${ }^{11}$ (Appendix 3 online). The approach was similar to that followed by recent studies like Vishwanathan and Meenakshi ${ }^{12}$, Chand and Jumrani ${ }^{13}$. Further, the share of sample population in each village with underintake of calorie as well as dietary nutrients was estimated. The villages were further categorized into four groups based on the severity of intake gap of each nutrient. The categories of under-nutrition defined were: 'extreme', if $75 \%$ and above of population in the village is deficit in recommended intake of a particular nutrient; 'high' if the share is $50 \%$ to $75 \%$; 'moderate' if the share is $25 \%$ to $50 \%$; and 'low' if less than $25 \%$ of the population shows deficit in nutrient intake.

A probit regression model was fitted to ascertain the major determinants that influence the calorie intake pattern of households. The model was specified as

$$
P_{i}=\alpha+\beta Z_{i}+\gamma E_{i}+\delta O_{i}+\theta S,
$$

where $P_{i}$ is the binary dependent variable that equals 1 if the household in question is showing deficit in calorie intake and 0 if not. Among the set of explanatory variables, $Z_{i}$ represents a vector containing variables on sociological and demographic characteristics of the household such as age, sex and education of the family head, household size, as well as caste affiliation of the household. $E_{i}$ is a vector that represents the economic status and access of the household and includes variables such as per capita expenditure of the household, the share of PDS in total cereal consumption, a dummy on access to institutional credit, and another dummy that defines whether any of the household members is holding a salaried job or not. The ownership of the household of productive assets such as land and livestock was represented by the vector $O_{i}$. The variable $S$ represents Simpson Index of Diversity (SID) that measures the diversity of consumption of the household in terms of various food items. It was estimated with the formula

$$
\mathrm{SID}=1-\sum_{i=1}^{n} P_{i}^{2}
$$

where $P_{i}$ is the proportion of $i$ th food item in total monthly consumption of all food by the members of the household. The monthly estimates were subsequently averaged to get the final estimate for the year under consideration. The index ranges between 0 and 1 , where its value moves towards 0 in case of absolute dependence on a specific food item only. A detailed account of the dietary diversity estimates for the study area is available in Parappurathu et al. ${ }^{14}$.

\section{Results and discussion}

\section{Food consumption pattern}

Table 1 shows the average consumption of various food items in the sample households in the selected villages. Cereals were the main source of dietary nutrients in all the villages, with rice and wheat being the main staples. Significant disparity in cereal consumption was noticed across the villages, with CSpur consuming the lowest at $11.92 \mathrm{~kg} / \mathrm{capita} / \mathrm{month}$, whereas villages like Ainlatunga and Bilaikani consumed almost double the amount of that of CSpur. The consumption of pulses, oils and fresh fruits on the other hand, was relatively lower (less than 1 $\mathrm{kg}$ /capita/month) in most villages except Ainlatunga and Bilaikani. On the contrary, vegetable consumption was quite high in most of the villages, with Dumariya (16.20 kg/capita/month), Ainlatunga (9.49 kg/capita/ month) and Bilaikani (13.81 kg/capita/month) topping the list. The villages of Bihar, particularly Arap and Baghakole, were far ahead in terms of milk consumption compared to others. Notably, the average consumption of non-vegetarian food was found to be quite low in majority of the villages, with the exception of Ainlatunga and Bilaikani. A general observation from the observed dietary habits of the sample villages is that, the diversity of food consumption was very low in most of them, with predominant dependence on cereals and vegetables for meeting their energy and nutrient requirements. Evidently, the consumption of fruits, milk (with the exception of Bihar), and non-vegetarian food items was much lower. All villages of Bihar and Jharkhand as well as two villages of Odisha (Sogar and Chandrasekharpur) belonged to this category, while Dumariya, Ainlatunga and Bilaikani were clear exceptions. The latter three villages were conspicuous by their exceptionally high consumption of almost all food items, in relation to the rest of them. Such deviation could be attributed to the variant eating habits in certain pockets of eastern India particularly in Odisha, attributable to their nature of work, caste and religious affiliations. These villages are dominated by OBCs, SCs and STs. They together account for $73 \%$ of the village population in Dumaria, 94\% in Ainlatunga and 99\% in Bilaikani. Further, two third of the population in each of these villages is engaged in heavy physical activities in 
RESEARCH ARTICLES

Table 1. Consumption of various food items in sample households of eastern India, 2011-12 (kg/person/month)

\begin{tabular}{llccccrrr}
\hline State & Village & Cereals & Pulses & Oils & Fresh fruits & Vegetables & Milk & Meat, fish and egg \\
\hline \multirow{2}{*}{ Bihar } & Arap & 18.72 & 0.68 & 0.74 & 0.71 & 8.35 & 13.01 & 0.05 \\
& Baghakole & 17.70 & 0.78 & 0.66 & 0.60 & 10.79 & 8.68 & 0.12 \\
& Inai & 13.40 & 0.60 & 0.41 & 0.87 & 6.54 & 4.36 & 0.34 \\
\multirow{5}{*}{ Jharkhand } & Susari & 12.51 & 0.62 & 0.38 & 0.35 & 4.21 & 6.04 & 0.11 \\
& Dubaliya & 16.33 & 0.32 & 0.53 & 0.29 & 6.81 & 0.79 & 0.31 \\
& Hesapiri & 14.02 & 0.51 & 0.33 & 0.08 & 6.77 & 0.20 \\
\multirow{5}{*}{ Odisha } & Dumariya & 21.57 & 1.46 & 1.15 & 0.72 & 16.20 & 4.93 & 0.79 \\
& Durgapur & 15.11 & 0.49 & 0.51 & 0.10 & 5.85 & 0.32 & 0.42 \\
& Sogar & 13.29 & 0.93 & 0.54 & 1.41 & 6.92 & 2.49 & 0.47 \\
& CSpur & 11.92 & 0.71 & 0.51 & 1.06 & 6.76 & 2.01 & 0.66 \\
& Ainlatunga & 20.16 & 1.60 & 0.83 & 1.67 & 9.49 & 0.47 & 0.87 \\
& Bilaikani & 25.87 & 2.12 & 1.09 & 1.47 & 13.81 & 2.12 \\
\hline
\end{tabular}

See Parappurathu et al. ${ }^{14}$ for further details on food consumption and expenditure pattern of the sample households.

Table 2. Average consumption of calorie and nutrients in sample households of eastern India, 2011-12 (Unit/person/day)

\begin{tabular}{|c|c|c|c|c|c|c|c|c|c|c|c|c|}
\hline State & Village & $\begin{array}{l}\text { Calorie } \\
\text { (Kcal) }\end{array}$ & $\begin{array}{l}\text { Protein } \\
(\mathrm{gm})\end{array}$ & $\begin{array}{l}\text { Fat } \\
(\mathrm{gm})\end{array}$ & $\begin{array}{l}\text { Iron } \\
(\mathrm{mg})\end{array}$ & $\begin{array}{l}\text { Zinc } \\
(\mathrm{mg})\end{array}$ & $\begin{array}{c}\beta \text {-carotene } \\
(\mu \mathrm{g})\end{array}$ & $\begin{array}{l}\text { Thiamine } \\
(\mathrm{mg})\end{array}$ & $\begin{array}{l}\text { Riboflavin } \\
\text { (mg) }\end{array}$ & $\begin{array}{l}\text { Niacin } \\
(\mathrm{mg})\end{array}$ & $\begin{array}{l}\text { Folic acid } \\
\quad(\mu \mathrm{g})\end{array}$ & $\begin{array}{c}\text { Vitamin C } \\
(\mu \mathrm{g})\end{array}$ \\
\hline \multirow[t]{4}{*}{ Bihar } & Arap & 2722 & 77 & 53 & 21 & 6.5 & 872 & 2.07 & 1.38 & 20 & 220 & 92 \\
\hline & Baghakole & 2988 & 84 & 50 & 24 & 7.5 & 827 & 2.28 & 1.40 & 23 & 228 & 99 \\
\hline & Inai & 2141 & 61 & 30 & 17 & 7.5 & 774 & 1.64 & 0.92 & 17 & 163 & 58 \\
\hline & Susari & 2007 & 58 & 33 & 16 & 5.7 & 441 & 1.47 & 0.91 & 15 & 140 & 34 \\
\hline \multirow[t]{3}{*}{ Jharkhand } & Dubaliya & 2443 & 57 & 25 & 9 & 4.9 & 620 & 0.75 & 0.62 & 14 & 107 & 71 \\
\hline & Dumariya & 4128 & 105 & 63 & 30 & 8.2 & 1786 & 2.45 & 1.55 & 29 & 281 & 167 \\
\hline & Durgapur & 2230 & 52 & 21 & 10 & 2.1 & 455 & 0.80 & 0.56 & 14 & 102 & 53 \\
\hline \multirow[t]{4}{*}{ Odisha } & Sogar & 2254 & 56 & 31 & 14 & 10.2 & 455 & 0.85 & 0.65 & 13 & 126 & 63 \\
\hline & Cspur & 1976 & 49 & 25 & 7 & 9.8 & 352 & 0.61 & 0.50 & 11 & 111 & 50 \\
\hline & Ainlatunga & 3296 & 81 & 39 & 17 & 9.2 & 969 & 1.26 & 0.94 & 19 & 229 & 104 \\
\hline & Bilaikani & 4651 & 116 & 55 & 23 & 5.9 & 1672 & 1.65 & 1.38 & 27 & 310 & 161 \\
\hline
\end{tabular}

Table 3. Calorie consumption by farm-size groups in sample households of eastern India, 2011-12 (Kcal/person/day)

\begin{tabular}{llcccc}
\hline State & Village & Marginal & Small & Medium & Large \\
\hline \multirow{2}{*}{ Bihar } & Arap & 2049 & 2634 & 2840 & 3333 \\
& Baghakole & 2401 & 2771 & 3139 & 3831 \\
& Inai & 2108 & 2005 & 2112 & 2292 \\
& Susari & 1890 & 1961 & 2158 & 2015 \\
\multirow{5}{*}{ Jharkhand } & Dubaliya & 2355 & 2001 & 2541 & 2790 \\
& Hesapiri & 2026 & 1988 & 2046 & 2067 \\
& Dumariya & 3908 & 4213 & 3961 & 4515 \\
\multirow{5}{*}{ Odisha } & Durgapur & 2199 & 2077 & 2310 & 2352 \\
& Sogar & 2237 & 2286 & 2149 & 2337 \\
& CSpur & 1943 & 1933 & 2130 & 1923 \\
& Ainlatunga & 2911 & 3319 & 3236 & 3585 \\
& Bilaikani & 4417 & 4620 & 4505 & 4984 \\
\hline
\end{tabular}

crop cultivation, dairying or non-farm manual work that are relatively more energy consuming.

\section{Calorie and nutrient intake}

The dietary profile of sample villages in terms of their calorie and nutrient consumption presented in Table 2 shows that, the intake of calorie and nutrients varied significantly across the villages. The average calorie consumption in Bihar varied in the range of $2007 \mathrm{Kcal} /$ person/day in Susari, to $2988 \mathrm{Kcal} /$ person/day in Baghakole. In Jharkhand also, the calorie consumption of respondent households fell in a similar range, except in Dumariya (4128 Kcal/person/day). The inter-village calorie disparity was the highest in Odisha with CSpur faring the worst (1976 Kcal/person/day) on the one hand, and Bilaikani registering the highest $(4651 \mathrm{Kcal} /$ person/day). The relatively higher calorie intake in villages like Dumariya, Ainlatunga and Bilaikani could be directly attributed to their higher consumption of cereals as indicated before. A perusal on calorie consumption by farm-size groups across the villages revealed that households possessing larger farms consumed more calories than that of lower landholdings (Table 3). The trend was pervasive across states, though with minor deviations in a few villages.

As in the case of calorie, the average intake of other nutrients also showed disparate trends in the villages under study. Protein intake was the highest in Bilaikani (116 gm), followed by Dumariya (105 gm) and Baghakole (84 gm) (Table 4). Dumariya stood ahead (63 gm) of 


\section{RESEARCH ARTICLES}

Table 4. Status of calorie and nutrient gap of sample population of selected households of eastern India, 2011-12

\begin{tabular}{|c|c|c|c|c|c|c|c|c|c|c|c|c|}
\hline State & Village & Calorie & Protein & Fat & Iron & Zinc & $\begin{array}{c}\beta- \\
\text { carotene }\end{array}$ & Thiamine & Riboflavin & Niacin & $\begin{array}{l}\text { Folic } \\
\text { acid }\end{array}$ & $\begin{array}{c}\text { Vitamin } \\
\mathrm{C}\end{array}$ \\
\hline \multirow[t]{4}{*}{ Bihar } & Arap & & & & & & & & & & & \\
\hline & Baghakole & & & & & & & & & & & \\
\hline & Inai & & & & & & & & & & & \\
\hline & Susari & & & & & & & & & & & \\
\hline \multirow[t]{4}{*}{ Jharkhand } & Dubaliya & & & & & & & & & & & \\
\hline & Hesapiri & & & & & & & & & & & \\
\hline & Dumariya & & & & & & & & & & & \\
\hline & Durgapur & & & & & & & & & & & \\
\hline \multirow[t]{4}{*}{ Odisha } & Sogar & & & & & & & & & & & \\
\hline & CSpur & & & & & & & & & & & \\
\hline & Ainlatunga & & & & & & & & & & & \\
\hline & Bilaikani & & & & & & & & & & & \\
\hline
\end{tabular}

'Extreme' under-nutrition (>75\% population deprived of recommended nutrient intake)

'High' under-nutrition ( $50 \%$ to $<75 \%$ population deprived of recommended nutrient intake)

'Moderate' under-nutrition ( $25 \%$ to $<50 \%$ population deprived of recommended nutrient intake)

'Low' under-nutrition (Less than $25 \%$ population deprived of recommended nutrient intake)

all others in terms of fat intake, whereas CSpur (25 gm) depicted the least. The villages such as Dubaliya, Hesapiri and CSpur were conspicuous by their low intake of iron and zinc. Similarly, villages like Susari, Hesapiri, Durgapur, Sogar and CSpur stood out on account of their low intake of almost all the vitamins. On the other hand, Arap and Baghakole of Bihar, Dumariya of Jharkhand as well as Ainlatunga and Bilaikani of Odisha were notable with their relative richness in intake of essential vitamins.

\section{Energy and nutrient intake gap in eastern India}

The villages were classified into four groups of undernutrition based on the calorie and nutrient intake gap of their sample population as depicted in Table 4. Among the 12 villages, one village was designated as 'extreme', 5 villages 'high', 2 villages 'moderate' and 4 villages 'low' based on their observed proportion of households with calorie gap. Evidently, CSpur was found to be housing more than $75 \%$ of its sample population that are short of the recommended calorie intake. Inai, Susari, Hesapiri, Durgapur and Sogar fell in the category of 'high' calorie under-nutrition, with $50-75 \%$ of their sample population being calorie-deprived. The calorie intake status of Arap and Dubaliya was also not inspiring as $25-50 \%$ of their population took lower calories than prescribed. Baghakole, Dumariya, Ainlatunga and Bilaikani were comparatively better-off with less than $25 \%$ of their respondents being designated calorie-deprived. The protein intake status of the sample villages was relatively better, with none of the villages falling under the 'extreme' category. However, Hesapiri, Durgapur and CSpur were notable for their 'high' protein under-intake status. On the contrary, the intake gaps of fat and iron were more pronounced with 2 of the villages designated as 'extreme' in terms of fat under-intake and five designated as 'extreme' in terms of Iron under-intake. In case of zinc, while 9 villages fell in the category of 'extreme' under-intake, rest of the three belonged to the 'high' category. The situation was alarming in the case of $\beta$-carotene intake with all 12 villages being designated as 'extreme'. There were five 'extreme' thiamine deficient villages and 8 'extreme' riboflavin deficient villages. Even Ainlatunga, a comparatively better-off village in terms of intake status of most other nutrients fell in the topmost category in case of Riboflavin. Similarly, 6 villages were reported to have 'extreme' folic acid under-intake. The status of niacin and vitamin $\mathrm{C}$ intake were relatively better with lower numbers of villages that fell in the top two classes of under-nutrition.

It is worth correlating the observed nutrient intake gap of the villages with the quality and diversity of their food consumption. As seen from Table 1, the villages like Arap, Baghakole, Dumariya, Ainlatunga and Bilaikani, with higher average consumption of major food items were low on the intake gap matrix. Among the above 5 villages, Dumariya exhibited the best nutritional status with 'low' intake gap of all nutrients except $\beta$-carotene. The households of this village not only consumed higher quantities of cereals and pulses, but also quality dietary items such as fresh fruits, vegetables, milk, meat, fish, egg, etc. which are rich in essential nutrients. The relatively higher proportion of people deficient in major vitamins in Ainlatunga could be attributed to their low consumption of milk. On the other hand, villages like Dubaliya, Hesapiri, Durgapur, Sogar and CSpur that fared low on the nutritional status were conspicuous by their low consumption of nutrient-rich food items. Durgapur, which fell in the top two categories of under-nutrition 
RESEARCH ARTICLES

Table 5. Status of calorie and nutrient gap of sample population across farm-size classes in eastern India, 2011-12

\begin{tabular}{|c|c|c|c|c|c|c|c|c|c|c|c|c|}
\hline Region & $\begin{array}{c}\text { Farm-size } \\
\text { class }\end{array}$ & Calorie & Protein & Fat & Iron & Zinc & $\begin{array}{c}\beta- \\
\text { carotene }\end{array}$ & Thiamine & Riboflavin & Niacin & $\begin{array}{l}\text { Folic } \\
\text { acid }\end{array}$ & $\begin{array}{c}\text { Vitamin } \\
\mathrm{C}\end{array}$ \\
\hline Bihar & $\begin{array}{l}\text { Marginal } \\
\text { Small } \\
\text { Medium } \\
\text { Large }\end{array}$ & & & & & & & & & & & \\
\hline Jharkhand & $\begin{array}{l}\text { Marginal } \\
\text { Small } \\
\text { Medium } \\
\text { Large }\end{array}$ & & & & & & & & & & & \\
\hline Odisha & $\begin{array}{l}\text { Marginal } \\
\text { Small } \\
\text { Medium } \\
\text { Large }\end{array}$ & & & & & & & & & & & \\
\hline
\end{tabular}

'Marginal' refers to households possessing land area less than or equal to 0.5 acres. 'Small', 'Medium' and 'Large' refer to tertile groups of households in respective order, with land area above 'Marginal'.

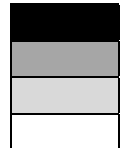

'Extreme' under-nutrition (>75\% population deprived of recommended nutrient intake)

'High' under-nutrition ( $50 \%$ to $<75 \%$ population deprived of recommended nutrient intake)

'Moderate' under-nutrition ( $25 \%$ to $<50 \%$ population deprived of recommended nutrient intake)

'Low' under-nutrition (Less than $25 \%$ population deprived of recommended nutrient intake)

for all the nutrients considered, was particularly noteworthy for its meager consumption of nutrient-rich dietary ingredients such as fresh fruits, vegetables, milk and other non-vegetarian items. The high level of $\beta$-carotene intake gap in the villages could be attributed to the fact that, this carotenoid is present in high quantities only in certain kinds of food items such as leafy vegetables, carrot, soyabean, mango, berries, ghee, butter, marine and fresh water fish, etc., which are either expensive or in short supply for the respondents. As the diversity in food consumption of sample villages is quite low with high dependence on cereals and low-value seasonal vegetables, the access to $\beta$-carotene sources appears to be therefore limited.

To understand the disparity in nutritional status across the farm-size classes, state-wise intake gap of major nutrients was assessed by pooling the villages in a state. The general trend as revealed from Table 5 suggests that, nutritional status of households improved as one moves from lower farm-size categories to larger ones. For instance, the marginal households in Bihar were at 'high' calorie gap whereas, the remaining three farm-size classes belonged to the 'moderate' intake gap category. Similarly, fat intake gap status changed from 'high' to 'moderate' and further to 'low' across marginal, small and the top two farm-size classes in Bihar. However, contrary to the general trend, the proportion of households short in nutrient intake was more among small farm-size class than in the case of marginal class in Jharkhand. The general rule of 'higher nutrient gap among lower farmsize classes' was found true even when all the sample households were pooled as a single group as illustrated in Table 5.

\section{Determinants of calorie gap}

Calorie intake being one of the most researched aspect in the literature on nutrition security in India, various factors that determine the calorie intake pattern of sample households was investigated upon in this section. Several socio-economic and demographic characteristics of the households such as age, gender, education of the household head, household size, caste affiliation, annual income of the household, its level of access to credit, share of PDS in cereal consumption, salaried employment of members, ownership of the household of productive assets such as land and livestock, diversity in food consumption, and so on were considered to have a bearing on calorie intake of households. The choice of the explanatory variables included in the analysis was guided by previous empirical literature on this aspect ${ }^{15-18}$. Accordingly, a probit regression model was fitted, taking calorie gap status of the households as the binary dependent variable and the other variables indicated above as explanatory variables. The results of the estimated model along with the computed marginal effects of each of the independent variables are presented in Table 6 . In the present context, marginal effect of a variable denotes the marginal change in probability of the household being calorie deficient with respect to each unit marginal change in the concerned explanatory variable. The overall fit of the model was significant at $1 \%$ level with pseudo $R^{2}$ value of 0.12 . The coefficient of the variable, 'age of the household head' was positive and significant with a marginal effect of 0.023 , suggesting that, households with older heads were at higher odds to be calorie insecure. Similarly, educational status of the household head was found to 


\section{RESEARCH ARTICLES}

Table 6. Estimates of binary probit regression on factors contributing to calorie gap of sample households and their marginal effects

\begin{tabular}{|c|c|c|c|}
\hline Variable & Coefficient & Standard error & Marginal effects $(\mathrm{d} y / \mathrm{d} x)$ \\
\hline Constant & -0.295 & 0.950 & \\
\hline Age of the household head (year) & $0.078 * *$ & 0.032 & $0.023 * *$ \\
\hline Age squared & $-0.001 * *$ & 0.000 & $-0.000 * *$ \\
\hline Education of the household head (year) & $-0.033 * *$ & 0.017 & $-0.009 * *$ \\
\hline Gender of the household head $($ male $=1$, female $=0$ ) & -0.042 & 0.286 & -0.012 \\
\hline Household size (no.) & 0.043 & 0.028 & 0.012 \\
\hline Caste dummy (general $=1$, others $=0$ ) & 0.009 & 0.175 & 0.003 \\
\hline Annual per capita expenditure (Rs) & $-0.000 * * *$ & 0.000 & $-0.000 * * *$ \\
\hline Share of PDS in cereal consumption (per cent) & $-0.006 * *$ & 0.003 & $-0.002 * *$ \\
\hline Occupation type $($ salaried $=1$, otherwise $=0)$ & $-0.375 * *$ & 0.147 & $-0.109 * * *$ \\
\hline Access to credit $(\mathrm{KCC}$ cardholder $=1$, otherwise $=0$ ) & $-0.871 *$ & 0.486 & $-0.254 *$ \\
\hline Land dummy (if owned land = 1 otherwise $=0$ ) & $-0.312 *$ & 0.182 & $-0.091 *$ \\
\hline Livestock dummy (if owned livestock $=1$, otherwise $=0$ ) & $-0.268 *$ & 0.170 & -0.078 \\
\hline Simpson Index of Dietary Diversity & $-1.711 * *$ & 0.874 & $-0.499 * *$ \\
\hline No. of observations & 487 & & \\
\hline Pseudo $R^{2}$ & 0.120 & & \\
\hline $\operatorname{LR~Chi}^{2}(13)$ & 68.340 & & \\
\hline Log likelihood & -250.384 & & \\
\hline
\end{tabular}

Dependent variable - calorie gap of households (deficit $=1$, otherwise $=0$ ).

$* * *, * *$ and $*$ significance at $1 \%, 5 \%$ and $10 \%$ respectively.

influence the calorie gap status of the household as evident from the negative and significant coefficient of the concerned variable. The above results make sense, as older individuals with lower educational attainments are supposed to be less aware on the nutritional requirements of his/her family members. On the other hand, gender of the household head was found to be insignificant, wherein female headed households in the sample did not show any particular vulnerability to malnutrition as reported by several past studies ${ }^{16,17}$. In similar lines, the family size of sample households was not found to be significantly influencing their calorie intake status. More importantly, the variable 'caste dummy' was insignificant, suggesting the absence of any linkage between food insecurity of households and their caste affiliation. This finding is particularly relevant, as caste affiliation of the households in eastern India does play a role in determining their overall social status.

Among the economic variables, the level of annual per capita expenditure of a household had a strong influence on its calorie intake. As obvious from the negative coefficient of this variable which is significant at $1 \%$ level, it could be easily inferred that the probability that a household is self-sufficient in calorie intake improves with the increase in its overall expenditure through the year. The coefficient of the variable, 'share of PDS in cereal consumption' was estimated to be -0.006 with a marginal effect of -0.002 intending that the probability of nutrition insecurity of a sample household would decrease by 0.002 units with a one unit increase in share of PDS cereal consumption. This is consistent with the finding of a number of past studies ${ }^{19-21}$ that revealed the role of PDS in augmenting nutritional security of households in India. Similarly, an assured and steady flow of income through salaried job of a member of the household is also proven to diminish the calorie deficiency of the household. The marginal effect of this variable was -0.109 (significant at $1 \%$ level), indicating its strong influence in addressing calorie deprivation. Access to formal credit through the ownership of Kisan Credit Card was also found to be favouring a household to achieve higher level of calorie intake. Ownership of land and livestock was another factor that contributed in reducing calorie deficiency of sample households as indicated by the magnitude and level of significance of their respective coefficients. Ownership of these assets certainly plays a role in improving the self-sufficiency of households, as indicated by previous studies. One of the most notable observations from the probit analysis was that, diversity in food consumption improves calorie sufficiency of the households. Evidently, the coefficient of the variable, Simpson Index of Diversity was significant at 5\% level with a relatively higher marginal effect of -0.499 . Several past studies have brought out such strong cause-effect relationship between dietary diversity and energy and nutrient intakes ${ }^{22,23}$.

In a nutshell, the above probit model makes it abundantly clear that, the calorie gap status of a household is dependent on a number of socio-economic and demographic variables that characterize its ability to get access to sufficient amount of nutritionally superior food. As the above exercise is limited only to calorie intake status of households, there is scope for further research on identifying the determinants of intake of other nutrients. 


\section{Limitations of the study}

Though the study follows a relatively novel approach to assess the prevalence of nutrition insecurity among the sample population, covering the intake of major nutrients, it suffers from certain limitations as outlined; firstly, it is assumed that, a particular food item irrespective of its source, quality and level of processing has the same nutrient composition. However, the authors acknowledge the fact that, changes in source and quality as well as level of cooking and processing can alter the calorie and nutrient content of food items. Secondly, it is also assumed that there is no distinction between calorie intake and calorie absorption, which again is a simplification that cannot be avoided in a socio-economic study like this. Lastly, the usual caveat regarding the recall bias associated with reporting of food consumption on a 30-day recall period also applies here.

\section{Conclusions}

This study assessed the level and pattern of food and nutrient intake in 12 villages of eastern India based on sample data collected through household-level surveys. The quantities of various food items consumed by the sample households and corresponding nutrient intake levels were assessed using standard estimation procedures. A general observation from the observed dietary habits of the sample villages is that, the diversity of food consumption was very low in most of them, with predominant dependence on cereals and vegetables for meeting their energy and nutrient requirements. Evidently, the consumption of fruits, milk (with the exception of Bihar), and nonvegetarian food items was much lower, with exception of a few. Significant disparity in levels of calorie and nutrient consumption was noticed across the villages, in line with the disparities in their food consumption pattern. In general, households with larger farm sizes were found to be better nourished, irrespective of the village or state to which they belonged.

The calorie and nutrient intake gap of the sample households were assessed to throw light on the overall nutritional status of the study area. The villages were subsequently classified into four categories based on their observed proportion of households with calorie gap. Out of all the villages studied, one village was designated as 'extreme', 5 villages 'high', 2 villages 'moderate' and 4 villages 'low'. Similar findings on intake gaps of other major nutrients like protein, fats, iron, zinc, vitamins, etc. were also reported. A number of socio-economic and demographic variables that determined the calorie deficit status of the households were identified and described based on a probit analysis. The results indicated that determinants such as age and educational status of the household head, annual per capita expenditure of the household, share of PDS in its cereal consumption, occupation type of the family members, access to formal credit, ownership of land and livestock and dietary diversity of the food consumed, significantly influenced the calorie deficiency status of a household. Notably, social status of a household, in terms of its caste affiliation, did not have any bearing on the nutritional status.

High prevalence of food and nutrition insecurity in eastern India as revealed by the study could significantly constrain the future development of the region. Proactive measures are necessary to address this persistent and deep rooted problem through devising systematic and timebound strategies that are designed with due consideration to the socio-economic and demographic characteristics of the target population. Though the above analysis is limited only to the sample area which is of relatively small coverage, the broad findings arising out of it have larger implications. The observed linkages between the nutrient intake and various socio-economic and demographic determinants are of substantive relevance not only for the eastern India, but for a considerable section of the developing world.

Competing interests: The authors declare that they have no competing interests, either personal or financial.

1. Agricultural Statistics at a Glance 2015, Directorate of Economics and Statistics, Ministry of Agriculture, Government of India, 2015.

2. von Grebmer, K. et al., 2016 Global hunger index: Getting to zero hunger, Bonn Washington, DC and Dublin: Welthungerhilfe, International Food Policy Research Institute, and Concern Worldwide, 2016.

3. Rapid Survey on Children (RSoC) 2013-14, National Report, Ministry of Women and Child Development, Government of India.

4. Gulati, A., Kumar, A. G., Shreedhar, G. and Nandakumar, T., Agriculture and malnutrition in India, Food Nutr. Bull., 2012, 33(1), 74-86.

5. Report on the State of Food Security in Rural India, MS Swaminathan Research Foundation, Chennai, 2008.

6. Swaminathan, M., Neo-liberal policies and food security in India: Impact on public distribution system, In Proceedings of the Conference on The Crisis of Neo-liberalism in India: Challenges and Alternatives, Tata Institute of Social Sciences (TISS) and International Development Economics Associates (IDEAs), Mumbai, 2009.

7. Khera, R., Trends in diversion of grain from the public distribution system, Econ. Polit. Wkly, 2011, 46(21), 106-114.

8. Khera, R., India's public distribution system: utilization and impact. J. Dev. Stud., 2011, 47(7), 1038-1060.

9. Nutrition Intake in India, Report No. $540(66 / 1.0 / 2$, NSS 66th Round (July 2009-June 2010), Ministry of Statistics and Programme Implementation, Government of India, 2012.

10. Gopalan, C., Rama Sastri, B. V. and Balasubramanian, S. C., Nutritive value of Indian foods (Revised and updated by Narasinga, B. S., Deosthale, Y. G. and Pant, K. C., reprinted in 2012), National Institute of Nutrition, Indian Council of Medical Research, Hyderabad, 1989.

11. Nutrient Requirement and Recommended Dietary Allowances for Indians, A Report of the Expert Group of the Indian Council of 
Medical Research, National Institute of Nutrition, Indian Council of Medical Research, Hyderabad, 2009.

12. Vishwanathan, B. and Meenakshi, J. V., The Changing Pattern of under nutrition in India: A Comparative Analysis across Regions, UNU-WIDER Research Paper No. 2006/118, World Institute for Development Economics Research, Helsinki, 2006.

13. Chand, R. and Jumarani, J., Food security and undernourishment in India: assessment of alternative norms and the income effect. Indian J. Agric. Econ., 2013, 68(1), 39-53.

14. Parappurathu, S., Kumar, A., Bantilan, M. C. S. and Joshi, P. K., Food consumption pattern and dietary diversity in eastern India: evidence from Village Level Studies (VLS). Food Sec., 7(5), 1031-1042.

15. Babatunde, R. O. and Qaim, M., Impact of off-farm income on food security and nutrition in Nigeria. Food Policy, 2010, 35, 303-311.

16. Mallick, D. and Rafi, M., Are female-headed households more food insecure? Evidence from Bangladesh. World Dev., 2010 38(4), 593-605.

17. Kassie, M., Ndiritu, W. S. and Shifero, B., Determinants of food security in Kenya, a gender perspective. Proceedings of the 86th Annual Conference of the Agricultural Economics Society, University of Warwick, United Kingdom, 2012.

18. Cock, D. N., D'Haese, M., Vink, N., van Rooyen, C. J., Staelens, L., Schonfeldt, H. C. and D'Haese, L., Food security in rural areas of Limpopo province, South Africa. Food Sec., 2013, 5(2), 269282.

19. Kumar, A. and Ayyappan, S., Food security and public distribution system in India. Agric. Res., 2014, 3(3), 271-277.
20. Kumar, A., Bantilan, M. C. S., Kumar, P., Kumar, S. and Shiv, J., Food security in India: trends, patterns and determinants. Indian J. Agric. Econ., 2012, 67(3), 445-463.

21. Himanshu and Sen, A., In-kind food transfers - II, Impact on nutrition and implications for food security and its costs. Econ. Polit. Wkly, 2013, 48(47), 60-73.

22. Kant, A. K., Dietary patterns and health outcomes. J. Am. Diet. Assoc., 2004, 104, 615-635.

23. Rose, D., Meershoek, S., Ismael, C. and Mc Ewan, M., Evaluation of a rapid field tool for assessing household diet quality in Mozambique. Food Nutr. Bull., 2000, 23, 181-189.

ACKNOWLEDGEMENTS. This paper is drawn from the research work undertaken under the Project 'Village Dynamics in South Asia (VDSA)' coordinated by the ICRISAT with funding support from the Bill and Melinda Gates Foundation (BMGF). The data collection was facilitated by National Institute of Agricultural Economics and Policy Research (NIAP), New Delhi, a network partner under the project. The guidance extended by Dr Ramesh Chand and Dr Mruthyunjaya while undertaking the study is gratefully acknowledged. The sustained cooperation from farmer interviewees, technical and secretarial assistance from Mr Shivjee, and the data collection and enumeration services from the field staff are thankfully acknowledged.

Received 27 June 2016; revised accepted 14 March 2019

doi: $10.18520 / \mathrm{cs} / \mathrm{v} 117 / \mathrm{i} 1 / 71-79$ 